\title{
The role of universities in Indonesia multi-hazard early warning system
}

\author{
Mujiburrahman ${ }^{1, *}$ \\ ${ }^{1}$ Charles Darwin University, College of Indigenous Futures, Arts and Society, Darwin, Northern Territory, Australia
}

\begin{abstract}
Indonesia is a disaster-prone region facing multiple hazards. The impact has cost human casualties, injuries, damages to assets, environment and regional development. In order to protect the people and assets, the government has increased the capacity to face and anticipate disaster which is through a multi-hazard early warning system (MHEWS). The academic sector in Indonesia, especially prominent universities such as Institut Teknologi Bandung and Universitas Gajah Mada has contributed positively to the development of MHEWS and the Land Slide Early Warning System. This research aims to examine the role of universities in Indonesia related to the establishment of an MHEWS in Indonesia by answering what are the roles and the challenges. The research methodology is through a desk study and document review of government and organizations reports using qualitative and descriptive analysis. The findings of the research indicate the role of universities in the MHEWS is in line with the concept of tri dharma of universities which research, higher education and outreach. This means the role of universities to conduct research related to early warning systems, higher education through having program studies related to disaster management and outreach the role to train the community, organizations, and government through professional networks. Unfortunately, the involvement of the eastern part of Indonesian universities still needs to increase capacity, awareness, and access in utilizing the MHEWS at the local level.
\end{abstract}

\section{Introduction}

Indonesia is one of the most disaster-prone countries in the world, Indonesia is also one of the largest archipelagos with a total area of $5.180 .053 \mathrm{~km} 2$ which $37 \%$ land area and $63 \%$ the ocean, in additional it as a total of $81.000 \mathrm{~km}$ coastline with over 16.056 islands named and reported to the United Nations [1]. Recorded by the National Disaster Management Agency (BNPB) in 2017, a total of 2341 disaster hit Indonesia which cased 377 people died, 3.5 million people displaced. The majority of disasters $99 \%$ are hydrometeorological which consist of 787 flood, 716 destructive winds, 614 landslides, 96 forest and land fires, 76 floods and landslide, 19 droughts, 11 high tides and abrasion whereas the geological disasters consist of 20 earthquakes and 2 volcanic eruptions [2].

The legal foundation for Disaster Management in Indonesia is stipulated in Law no 24/2007. The early warning system (EWS) is regulated in article 44 until 46 of Law No. 24/2007 which mandated that the implementation of disaster management with the potential situation of disaster must include activities of preparedness, early warning (EW) and disaster mitigation [4]. Furthermore, it is regulated in Government Regulation No $21 / 2008$ on the implementation of disaster management which becomes the basis for decision making, early warning activities, institutions authorized for monitoring risk and submit the results to $\mathrm{BNPB}$ and Local Disaster Management Agency (BPBD) based on the location and level of disaster [4].

The government of Indonesia has shown commitment and political will for issues related to disaster management. The Vice President of Indonesia stated that "Increasing number of incidents in Indonesia is necessary to anticipate and grow $s$ culture of awareness to reduce disaster risk. The disaster has a multi-dimension characteristic so that all disciplines of science have to contribute solutions towards disaster. Always dynamic and has to be done through prevention" [5]. One effective way is through establishing an early warning system. Unfortunately, a limited amount of research has been conducted on a multi Hazard Early Warning System (MHEWS). Indonesia being a disasterprone area have a high risk of being hit by a disaster.

The objective of this study is to examine the role of universities in Indonesia related to the establishment of a MHEWS in Indonesia. There are two main questions that this wants to address:

1. What are the roles of the academic institutions in the development of the Indonesia MHEWS?

2. What are the challenges of the involvement of universities in MHEWS?

\footnotetext{
Corresponding author: mujiburrahman@cdu.edu.au
} 


\section{Methodologies}

The research is based on a desk study through an overview and analysis of available literature related MHEWS in Indonesia. Legal documents such as law 24/ 2007 and Government Regulation No. 21/2008 were used as the basic foundations EWS in Indonesia. Draft Presidential Decree on a National MHEWS in Indonesia provided the basis for analysis of the development of an Indonesian MHEWS. These documents were derived from BNPB. Data collections used secondary data from libraries, government, Non-Governmental organizations, universities through internet and electronic databases.

This paper is divided into 4 sections starting with the launch of MHEWS. Second, explaining the role of universities in MHEWS in Indonesia using the lenses of tri dharma as the three pillars of education, and third, the challenges faced by universities. The final section sums up the research with a conclusion and recommendation for the future activities.

The limitation of the study is that it is solely focused on desk study to gather data about MHEWS in Indonesia. Most documents used are still in the Indonesia language hence the minimal amount of literature about MHEWS in Indonesia that are in the English language. Proposed for future research to utilize primary data collection methods such interviews, focus groups discussion with relevant stakeholders.

\section{Results and discussion}

\subsection{The launch of the MHEWS in Indonesia}

The background for the launch of the MHEWS is that the Indonesian government recognizes that there needs to be a shift from single hazard approach to multi-hazard approach. Thus, collaboration between universities, government agencies becomes more important. Where possible, EWS should link all hazard-based systems. Economies of scale, sustainability and efficiency can be enhanced if systems and operational activities are established and maintained within a multi-purpose framework that considers all hazards and end-user needs. MHEWS will also be activated more often than a single - hazard warning system, and therefore should provide better functionality and reliability for dangerous highintensity events, such as tsunamis, that occur infrequently. Multi-hazard systems also help the public better understand the range of risks they face and reinforce desired preparedness actions and warning response behaviours.

During the National Disaster Preparedness day on 26 April 2017, the Head of the National Disaster Management Agency (BNPB), Willem Rampangilei launched 3 applications to detect early disasters. The three applications are named InaWARE, InaSAFE, and MHEWS [6]. InaWARE is a monitoring application tool and support function in decision making under the Disaster Management Early Warning and Decision Support Capacity Enhancement Project in Indonesia [7].
InaSAFE is software that produces realistic natural hazard impact scenarios for better planning, preparedness and response activities. It provides data to scientists, local governments and communities to provide insights into the likely impacts of future disaster events [8].

Another product of the InaSAFE is the near Realtime earthquake impact assessments following recent earthquakes in the Indonesia region. Shakemaps of earthquake ground shaking are produced by the BMKG and used by the BNPB to produce InaSAFE impact assessments within minutes of an earthquake. This information is used by disaster managers to help them understand the potential scale of a disaster and to respond faster to the hardest hit communities. This is particularly important in the first few hours after a large earthquake when it may be difficult to get accurate onthe-ground information [9].

MHEWS is a prediction of the weather prediction information system. The results of these predictions are temporarily used only for Precautions and Preparedness within BNPB such as Head of BNPB, Centre for Data and Information Community (PUSDATINMAS), Operation Control Centre (PUSDALOPS), all Echelon 1 personnel and PUSDALOPS of BPBD in Indonesia. Currently, MHEWS systems are continuously being developed. Verification and field testing is also being conducted for continuous improvement. Hydrometeorological disaster prediction is processed from InaRISK data source of BNPB, BMKG, Public Works and Public Housing (PUPR), Ministry of Energy and Mineral Resources (ESDM), Agency of Assessment and Applied Technology (BPPT), National Institute of Aeronautics and Space (LAPAN) and Institute Technology Bandung (ITB). This prediction is the result of the overlap between the hydro-meteorological risk map index from InaRISK and weather prediction using Weather Research and Forecasting (WRF). Verification of weather prediction results uses data from BMKG [10]. There are four main features on the MHEWS: (1) Weather Prediction: Rainfall prediction, wind speed and direction, air temperature, air pressure, and relative humidity for every 3 hours for the next 3 days. (2) Hazard Index: a risk index for flood, flash flood, landslide, drought, and extreme weather hazard. (3) Hazard Prediction: Hazard prediction which obtained from a combination of rainfall index produced from weather prediction and in risk hazard index and (4) Hazard Warning: Hazard warning based on weather prediction and in risk hazard indexes. The objectives of the applications are to monitor all the disaster data and information, which is used to provide reliable early warning. BNPB especially PUSDALOPS at the time of disaster will directly control and analyse the disaster using these applications. 


\subsection{The update of the draft presidential decree on MHEWS in Indonesia}

According to BNPB in the Urgency Draft of Presidential Decree on National MHEWS there are four main issues related to the technical aspect which are [11]:

- EWS in Indonesia is still spread in various line ministries/ institutions and have not been well coordinated.

- EW monitoring and services for various hazards are individually functioning and are not integrated into one national system for multi-hazard.

- EW has not yet effectively informed and disseminate to the community, not enough follow up or community response, not yet optimal in utilizing science and technology and technical knowledge for monitoring/ analysis and implementation based on climate modelling and remote sensing.

- Need up to date EW technology to provide optimal services to the community.

The picture below is the concept for MHEWS.

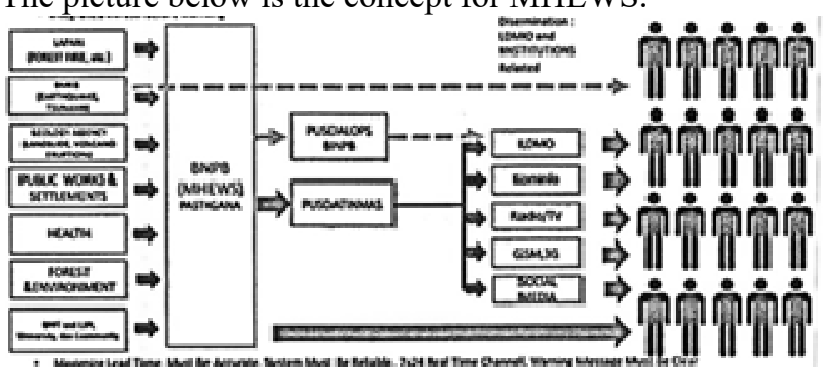

Fig. 1. The concept of warning information flow - MHEWS in Indonesia (BNPB, 2017)

On 24 October 2016, the Coordinating Minister for Human Development and Culture (MENKO PMK) conducted a meeting with line ministries to develop a MHEWS. The main problems about EWS in Indonesia are that it is not integrated, standards such as the content of the EW (level of danger) and the dissemination (media to spread the information). BPPT concept for MHEWS has been developed to build upon the already established tsunami EWS which have been installed in Nias and Aceh [12].

To lead the coordination mechanism at a higher level of the hierarchy, the MENKO PMK - represented by the Deputy Coordinator for Social Vulnerability and Impact of Disaster conducted a coordination meeting for the integration of the EWS on 16 November 2017. The development of the draft presidential decree has started since 2016 to provide a legal umbrella for the implementation of the MHEWS that is integrated nationally and have a legal foundation to support it. There are many individual EWS that have been developed by each line ministries which have not been properly coordinated and collaborated within the BNPB system. Therefore, to ease the integrated and comprehensive monitoring, an integrated early warning system at the national level has a purpose the improve the effectiveness of the current EWS in place. The next step for the formulation of the legal basis between each ministry is the coordination meeting of each legal department from each ministry to discuss and draft the presidential decree [13].

The recent coordination meeting was conducted on 16 January 2018 to discuss the following agenda (1) Introduction by the deputy, MENKO PMK, (2) Presentation on the academic draft of the integration of the Draft Presidential Decree on National Integrated MHEWS by BNPB and Discussion and inputs for Draft Presidential Decree.

A total of 30 participants from government official was invited to the meeting BNPB, PUPR, Fire: Ministry of Environment and Forestry (KLHK), Ministry of Agriculture (KEMENTAN), Ministry of Communication and Information (KEMENKOMINFO), Ministry of Research, Technology and Higher Education (KEMEN RISTEKDIKTI), Ministry of Health (KEMENKES), BMKG, BPPT, LAPAN, Geospatial Information Agency (BIG), Indonesian Academy of Sciences (LIPI), Nuclear Energy Regulatory Agency of Indonesia (BAPETEN), ITB, ESDM and Indonesian Broadcasting Commission (KPI). From 30 participants invited only 1 is from an academic institution which is ITB.

From the discussion above, there has been the significant progress of government institution in discussing the MHEWS, however, there is still limited participation of the academic institutions and community organizations in discussing the development of a national EWS.

\subsection{The role of universities in MHEWS in Indonesia}

This section will discuss the questions related to the research topic on the role of universities in the development of a MHEWS in Indonesia. The framework to discuss the roles will be linked to the concept of tri dharma of universities in Indonesia which is research, higher education, and outreach which was introduced in Law No 22/1961 on higher education [14]. Future research conducted by the disaster management studies in Indonesia can focus on early warning systems at the local levels.

The first role of universities related to early warning systems are the advocates of Sendai framework. All these efforts are in line with the government commitment at the international level for the Sendai framework for disaster risk reduction 2015 - 2030 [4]. Specifically, in paragraph 36 (j) which states that "Academia, scientific and research entities and networks to focus on the disaster risk factors and scenarios, including emerging disaster risks, in the medium and long-term; increase research for regional, national and local application; support action by local communities and authorities, and support the interface between policy and science for decision-making" [15].

BNPB has prepared the Master Plan for a National Level Integrated MHEWS which will be developed in the upcoming years. This concept is in line with the development of preparedness activities through early 
warning with is part of the national government MidTerm Development Plan for 2015-2019. To develop an integrated early warning system, it must have an institutional arrangement with 12-line ministries which have the technical capabilities to monitor the hazards such as:

- Tsunami: BMKG, BPPT / RISKTEKDIKTI, and LIPI

- Flood: PUPR, BMKG, and LAPAN

- Volcanic Eruption; ESDM

- Land Movement: ESDM, LAPAN

- Drought: BMKG, KEMENTAN, and LAPAN

- Forest and Land Fire: KLHK and LAPAN

- Earthquakes: BMKG, BPPT/RISKTEK, LIPI

- Epidemic: KEMENKES

- Nuclear: BAPETEN

- Technological Industry: Ministry of Industry and Trade (KEMENRINDAG)

The second role is that universities/ academic institutions supply the human resources of technical institutions who conduct disaster/ risk monitoring. The majority of government civil servants are from bachelor background, the higher the education, the higher position in government. An example is that of the current Head of BMKG was previously the rector of UGM. She has also lead the development of the Landslide early warning system (LEWS) in Indonesia [16].

Thirdly, support the government in conducting the risk assessment, using the methodology to calculate the risk which refers to the general guidelines Indonesia disaster risk assessment in Head of BNPB Regulation no. 2 and 3 in 2012. There is one application called InaRISK and it is a portal that summarizes the result of disaster risk assessment using ArcGIS server as data services that describe disaster-prone areas, impacted the population, potential physical loss (in Rp), economic potential loss (in Rp), and potential environmental damage (in ha). United Nation Development Program (UNDP) has contributed to the establishment of InaRISK by providing data services which have been the essential data in InaRISK. InaRISK is linked to disaster management plan which enables users to monitor the decline of disaster risk index. InaRISK also serves as a tool for monitoring the decline of disaster risk index as it is also linked to the realization of disaster risk reduction programme implementation. InaRISK has been launched formally by the Head of BNPB on 10 November 2016 attended by the representatives from Government Line Ministries, United Nations, donor countries, international and local NGOs, and other relevant Government institutions. In general, InaRISK serves as a basis for development planning, particularly on disaster risk reduction programme. InaRISK is to help its stakeholders particularly national and sub-national Government as well as communities in understanding the disaster risks and developing the disaster management plan. InaRISK also to have the following function [17]:

- Serve as a mechanism for spatial data sharing in a form of GIS service.
- Provide spatial data for specific purposes such as MHEWS, spatial planning, and revision, Global Centre Disaster Statistic (GCDS), etc.

- Develop policies and strategies for implementing disaster risk reduction programme.

- Monitor the progress of disaster risk index decline as it is linked to the disaster risk reduction programme implementation in the disaster plan.

Fourth, the role of universities to train BPBD in EW. Besides understanding the risk, another problem being faced in the EWS is the capacity of local government especially BPBD to respond. There are 34 provinces and 541 regencies/ municipalities that their human resources are needed to be supported both in quantity and quality. Moreover, they are lack of competency and professionalism. These factors give impacts on public service. It is required for personnel who are competent and professional so that the service can run well [18]. One example is from ITB which is involved in the development of applications for the flood early warning system for a web-based application and providing training to BPBD as well.

The fifth role is the establishments of academic networks such as Indonesian Association of Disasters Experts (IABI) and University Forum Disaster Risk Reduction (FPT PRB). The academic sector has pushed for the greater scientific contribution towards the early warning system in Indonesia. 350 Disaster experts from academics, bureaucrats, research institutes, disaster management practitioners and disaster-affected community members have declared the establishment of IABI as a nonprofit professional organization on June 5, 2014, simultaneously with the Annual Scientific Meeting in Surabaya. On the occasion have been prepared Blueprint and Roadmap Research on Disaster in Indonesia. During the period 2014-2017, research was directed and focused on the development of Early Warning System especially for tsunami disaster, flood/flash flood, drought, land and forest fire and mass movement/landslide.

IABI recommended to the government to immediately establish a national consortium that is in charge of designing a hydrometeorological disaster EWS or climate-related disaster. IABI have coordinate with BMKG, BNPB, LIPI and related stakeholders to prepare an accurate EWS up to the region. IABI urges the mass media to participate in providing guidance to the community related to a disaster situation. Mass media, especially electronic media, are asked to actively participate in broadcasting an early warning system to the seconds of extreme rainfall as electronic media also broadcast earthquake warning. Tri Handoko who also served in the Extreme Weather Working Group of IABI said the need for an integrated coordination system between BMKG, BPPT, BNPB and LIPI in mapping the potential for disaster and weather climate patterns to prevent the occurrence of casualties.

During the 3rd Annual Scientific Meeting at Bandung, West Java Provinces on 23-24 May 2016, there a session specifically related to EWS which are called 'new paradigm in Risk Warning towards SDGs'. 
A total of 17 papers was submitted and presented to provide a contribution towards understanding the hazards related to e geological, hydrometeorology, biological and technological failures hazards in Indonesia.

On the other hand, FPT PRB was established on 27 June 2008 as a national platform for coordination, communication, information sharing and collaborations between universities focusing on DRR issues. As an open membership forum, in 2012 a total of 46 universities are registered as members that consist of 53 disaster management centers and 25 study programs related to disaster studies.

Six, Strengthen the roles and collaborations with BNPB. BNPB has conducted a MoU with various academic institutions from 2010 up until 2014 such as Kristen Satya Wacana Salatiga University, Jember University, ITB, UGM, Bogor Agricultural Institute, Andalas University and Riau University. Many more universities have conducted coordination with BNPB, even without a MoU.

Based on the 3rd International Conference on EW on 27-29 March 2006 in Bonn, Germany, the science and academic community has a critical role in providing specialized scientific and technical input to assist governments and communities in developing early warning systems. Their expertise is central to analyzing natural hazard risks facing communities, supporting the design of scientific and systematic monitoring and warning services, supporting data exchange, translating scientific or technical information into comprehensible messages, and to the dissemination of understandable warnings to those at risk [19].

10 years after the conference in Bonn, the Sendai Framework have emphasized the importance of both the inclusion of the MHEWS and also the role of universities in DRR.

Universities in Indonesia must have a role in producing more studies on EW that are integrated and multi-hazard which can be a basis for policymaking. Universities have an important role to build the capacity of local government in disaster management. The Head of BNPB mentions that universities have an important role in disaster management. No matter form what university you are, your contribution to disaster management is more important. University has to understand how disaster management efforts in pre, during and post-disaster. Disaster research required various science-based approaches. The university has that capability to conduct researches. Not only in disaster management directly during an emergency, but researchers in different topics can be produced such as disaster risk reduction, prevention, and preparedness, spatial management, rehabilitation process, reconstruction or training [20].

As an attempt to synergizes and identifies the muchneeded disaster-related research/ studies to make national requirements, the former Head of BNPB, Dr. Syamsul Maarif had the initiatives to organize the 1st Annual Scientific Meeting on Disaster research in Surabaya on 3-5 June 2014. The first meeting formulates the Blueprint of disaster research for 2015 2019 and the establishment of IABI.

The IABI structure was designed to meet the needs of research and technological enhancement of 12 specific disasters as described in the National Disaster Management Plan 2015 - 2019 and the draft academic of Master Plan for 12 Disaster as formulated in 2013. There are 10 Working Groups (WG) for each disaster threats as follows WG Earthquake, WG Tsunami, WG Land Movement, WG Flood and Flash Flood, WG Drought, WG Extreme weather, WG Forest and Field Fires, WG Epidemic and Plague, WG Abrasion and Extreme Waves and WG Technological Failure.

The twelve universities that have signed a memorandum of understanding with BNPB to focus on each specific hazards such as ITB (earthquake) located in Bandung, UNSYIAH (tsunami) in Aceh, UGM (landslide) in Yogyakarta, UNDIP (flood) in Semarang, UNUD (drought) Bali, UI (extreme weather) in Jakarta, IPB (land and forest fire) in Bogor, UPN Veteran Yogyakarta (volcano) in Yogyakarta, UNHAS (erosion) in Makassar, and UNAIR (epidemic and disease outbreak) in Surabaya, UNAND (abrasion and extreme wave) in Padang and ITS (industrial accident) in Surabaya [21]. Below is a figure to show the spread of universities and focus on research.

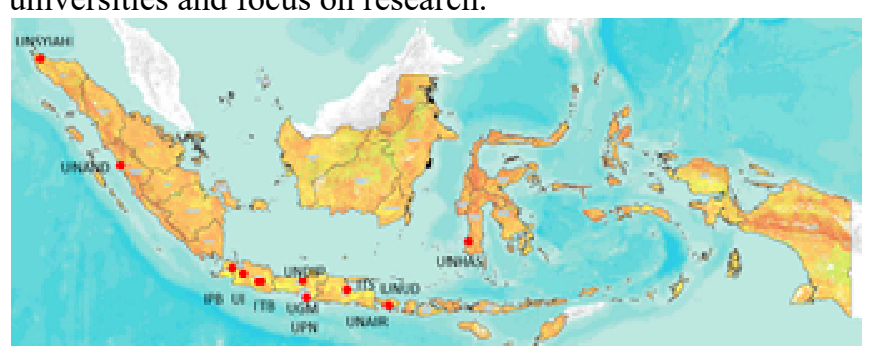

Fig. 2. Universities and focus area of research on disaster studies (BNPB, 2017) Note: InaRISK modified by Author)

Based on the picture above the majority of universities with a MoU and involved in the IABI are on the Java Island in 6 universities. Which means that 50\% are located in Java. 2 in Sumatra (16\%), 1 in Bali (8\%) and 1 in Sulawesi $(8 \%)$. Unfortunately, the maps show that there is the lack of representation form the eastern part of Indonesia such as Nusa Tenggara, Maluku, and Papua. Even the largest island in Indonesia, Kalimantan has no representation.

IABI mentions the need for an integrated coordination system between BMKG, BPPT, BNPB, and LIPI in mapping the potential for disaster and weather climate patterns to prevent the occurrence of casualties [22]. Starting from October 2016 during Disaster Risk Reduction Month in Manado, IABI focus on research and technology advancement for early EWS such as [23]:

- Provide a scientific reference for EWS implementation based on a lesson learned and best practices found in both local and international field of practice. It is expected that all research and lesson learned from IABI will be the foundation for any future disaster-related policies in Indonesia. 
- Create a concept of EWS integrations for specific disaster threats.

- Support the government to develop appropriate knowledge, technology, and expertise to reduce the risk of disaster

- Promote the use of advanced technology in developing EW and disaster risk reduction system as well as strengthening research and development.

- Enhance preparedness to face disaster

- Assist others stakeholders in integrating risk sensitive considerations into development planning and implementation and advancing a culture of safety and resilience

The only university which has a direct collaboration with the MHEWS is ITB. All other universities do not have a direct connection with the establishment of MHEWS in Indonesia. BNPB continues to cooperate with UGM Yogyakarta for installing the landslide early warning system. Installation of the LEWS has an objective to reduce disaster risk index in Indonesia. In 2017 they have installed 24 locations in Indonesia [24]. Despite the MoU with BNPB, UGM was not directly involved in the process of establishing the MHEWS in Indonesia. Other universities have yet to show contribution towards the Multi-Hazard Early Warning System in Indonesia.

Seven, role to support the government programs and strategic plans from RISTEKDIKTI in 2016. They have formulated the National Research Masterplan for 2015 2045. In the master plan, it mentions the problems related to EW such as considering the important aspect of disaster management, science, and technology. Especially in terms of disaster risk reduction, both before and after the disaster. Modelling and simulation can be used to detect the occurrence of disasters, but the timeliness is difficult to determine, so people still often do not trust in the use of technology. Therefore, the accuracy of EWS needs to be continuously improved and this is precisely the important contribution of disaster research. Implementation in the field often experiences obstacles [25].

Key research activities considered to be important for disaster risk reduction include several issues, both at the level of providing technology products and increasing community capacity in disaster risk reduction. Beyond that, various products of EWS designed with a multidisciplinary approach are needed to respond to the integrated emergency action. Equally important in addressing this disaster problem is the involvement of the community in disaster risk reduction needs to be improved, either through capacity-building technology based on local wisdom as well as building the sociocultural capacity of the community towards disasterresilient communities.

The master plan for the disaster management research in Indonesia covering each phase of disaster and each type of hazards categorized in groups. The fourmain aspect in disaster management research in Indonesia is related to technology and disaster management of Geological hazards, Hydrometeorological hazards, Forest and lands fires and the Environment. An aspect of EWS falls under the category of prevention and preparedness. Another important factor for future disaster research is the aspect of legal frameworks and disaster awareness in the community which is a cross-cutting issue in all four sectors. The explanation can be seen below in figure 3 .

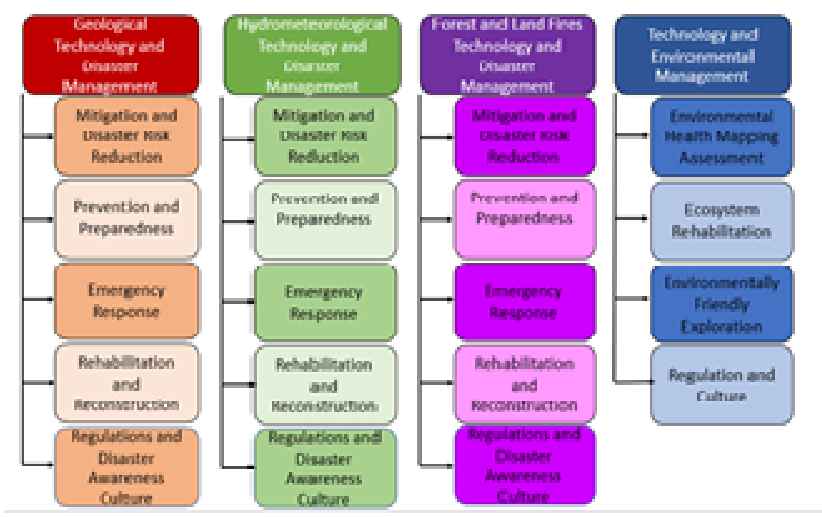

Fig. 3. Themes and topic of focus for disaster research (RISTEKDIKTI, 2017)

\section{Challenges of the involvement of universities in MHEWS}

While there is major improvements and capacity building initiatives have been built in post-disaster recovery regions Aceh, Padang, and Yogyakarta, the rest of Indonesia still far behind development. An interesting study was conducted by Mercy Corps and ITB on the role of Universities in DRR in the eastern part of Indonesia. The findings show limited roles of universities due to low capacity, awareness, and communications related to DRR. Furthermore, the challenges are:

"Lack of risk awareness among policymakers of each stakeholder group (universities, local government etc.), DRR not yet a local priority, lack of coordination, communication, and collaboration for DRR between involved stakeholder groups and difficult geographic condition and lack of infrastructure in eastern region of Indonesia hamper communication and coordination for DRR implementation" [26].

Due to lack of capacity in universities in Indonesia, only two top universities are involved in the development of policies and systems at the national level. First ITB and second UGM, ITB being directly involved and acknowledged in MHEWS and even developing flood warning systems, whereas UGM has developed the LEWS. Even though other universities have conducted efforts and research on EWS, they have not been significant at the national level.

\section{Conclusions and recommendations}

Based on the above findings above, the conclusion of the research are:

- The role of universities in the MHEWS is in line with the concept of tri dharma of universities which 
are research, higher education, and outreach. This means the role of universities to conduct research related to early warning systems, higher education through having program studies related to disaster management and outreach the role to train the community, organizations, and government.

- The main challenges are related to the access of universities towards the MHEWS at the national level. Only ITB have the direct access and acknowledgment in the process of the developing the MHEWS in Indonesia. Unfortunately, the spread and outreach of others universities related to MHEWS, especially in the eastern part of Indonesia is still minimal.

Recommendations are as follows:

- The need for an MHEWS for all the hazards identified in the National Disaster Management Plan 2016-2019 and not just Hydro-Meteorological Hazards such as flood, landslide, extreme weather, fires, and drought.

- More concerns about the lack of engagement with the eastern part of Indonesia in regards to the involvement of universities in the National Multihazard early warning system and involvement in the IABI. Even if the majority of the population are in Java island, priority should be provided to the eastern part of Indonesia which are least developed.

- The need for a legal umbrella for the MHEWS in Indonesia. Especially the clear regulation of regulated cooperation's between government agencies at the national level (horizontal partnership) and cooperation between national and local government (vertically partnership). Most importantly the cooperation between the universities and the government including the IABI or FPT PRB as the main forum for cooperation. Need to accelerate the enactment of the presidential decree.

- In order for the success of the MHEWS in Indonesia, investment must be made in building the capacity of the local government in utilizing applications from such as MHEWS, InaRISK, InaWARE, and InaSAFE. An opportunity that IABI and universities can contribute to the training of local government officials on early warning for rapid decision making in an onset of a disaster.

I would like to say thank you to LPDP scholarship for funding my Ph.D. at Charles Darwin University. Especially appreciate the support of Akhilesh Surjan and Jonatan Lassa as my supervisor for my research. Thank you to the Institute of Resource Governance and Social Change support of networking and development in East Nusa Tenggara. Save the Children for developing my career as a Humanitarian Coordinator, JICA for hiring me as a consultant for the JICA project for enhancing the disaster management capacity of BNPB and BPBD in Indonesia. Appreciate towards IFRC Danish Red Cross for supporting my initial year as a humanitarian worker in Indonesia.

\section{References}

1. Geospatial Information Agency, Indonesia - Report 16.056 Named and Coordinated Islands to PBB, New York. August 7-18 (2017) Retrieve from: http://big.go.id/rilis-pers/show/page-2329

2. S.P. Nugroho 2.341 Disaster Events, 377 Killed and 3.5 Million Refugees and Suffers from Disaster in 2017). National Dsister Management Agency. (2017), Retrieve from https://bnpb.go.id/2341kejadian-bencana-377-tewas-dan-35-juta-jiwamengungsi-dan-menderita-akibat-bencana-tahun2017

3. Law No. 27 of 2007 concerning Disaster Management

4. Government Regulation No. 21 of 2008 concerning the Implementation of Disaster Management.

5. S.P. Nugroho, BNPB: Vice President JK: Grow Disaster Awareness Culture to Reduce Disaster Risk, (2017)

https://www.bnpb.go.id/home/detail/3360/VicePresident-JK:-Grow-Disaster-Awareness-Culture-toReduce-Disaster-Risk

6. C.M. Rahayu, BNPB Launches 3 Applications for Early Detection of Disaster Potential in https://news.detik.com/berita/d-3484118/bnpbluncurkan-3-aplikasi-untuk-deteksi-dini-potensibencana

7. Humanitarian Open Street Map Team, USAID | BNPB | InAWARE: Disaster Management Early Warning and Decision Support Capacity Enhancement Project in Indonesia (2016) https://www.hotosm.org/projects/usaid bnpb inawar e disaster_management early warning and decisio n support capacity or http://inaware.bnpb.go.id/inaware/

8. InaSafe, InaSAFE postcard, (2016)https://github.com/inasafe/inasafegraphics/blob/master/inasafe-postcard/Postcardback2016-en.pdf or http://inasafe.org/

9. InaSAFE, Realtime Earthquake Reports, http://realtime.inasafe.org/realtime/

10. BNPB Welcome to Hydro-Meteorological Hazard Potential in Indonesia, (2017), http://mhews.bnpb.go.id/en/home

11. BNPB. Urgency Draft - Presidential Regulation on National Systems for Multi-Threat Disaster Early Warning, Directorate of Preparedness, National Disaster Management Agency. Page 10(2017)

12. Kemko PMK, Government Seeks to Develop MultiThreat Early Warning System (2016). https://www.kemenkopmk.go.id/artikel/pemerintahupayakan-pengembangan-sistem-peringatan-dinimulti-ancaman

13. Kemenko PMK, Rakor Ranprepres MHEWS, Early Warning System Integration, November 16, 2017. accessed on http://kemenkopmk.go.id/artikel/rakorranperpres-mhew-integrasikan-sistem-peringatan$\underline{\text { dini }}$

14. Law No. 22 of 1961 concerning Higher Education

15. UNISDR, Sendai Frameworks for Disaster Risk Reduction 2015-2030, 
https://www.unisdr.org/we/coordinate/sendaiframework

16. BNPB,. BNPB Install Landslide Early Warning System in 24 Locations, (2016) https://www.bnpb.go.id/home/detail/3402/BNPBInstall-Landslide-Early-Warning-System-in-24Locations

17. BNPB, Guide to Knowing Disaster Risk. (2016). http://inarisk.bnpb.go.id/panduan singkat ina.pdf

18. BNPB, BNPB Design Diploma Degree in Disaster Management, https://www.bnpb.go.id/home/detail/3367/BNPBDesign-Diploma-Degree-on-Disaster-Management

19. UNISDR, Third International Conference on Early Warning (EWC III) hosted by the Government of Germany under the auspices of the United Nations, from 27 to 29 March 2006 in Bonn, Germany. Page 4 http://www.unisdr.org/files/608 10340.pdf accessed on June 23, 2017 at 1.49 am (2006),

20. BNPB, Important Role of University in Disaster Management, (2017), https://www.bnpb.go.id/home/detail/3354/ImportantRole-of-University-in-Disaster-Management,

21. BNPB Memorandum of Understanding With 12 Universities in Disaster Management. (2013). https://www.bnpb.go.id/home/detail/1288/notakesepahaman-bnpb-dengan-12-perguruan-tinggidalam-penanggulangan-bencana

22. IABI, Indonesia Needs a Fast EWS System (2016) http://www.iabi-indonesia.org/?p=568

23. IABI, Indonesian Disaster Expert Association, Brochure, Distributed in October 2016 Disaster Risk Reduction Month in Manado 13-15 October 2017. Technical Session \#2 International Seminar for Research and Technology on DM (2016), http://2016.peringatanbulanprb.net/rangkaiankegiatan/

24. BNPB, BNPB Install Landslide Early Warning System in 24 Locations (2016). https://www.bnpb.go.id/home/detail/3402/BNPBInstall-Landslide-Early-Warning-System-in-24Locations

25. RISKTEKDIKTI. National Research Master Plan for 2017-2045. (2017), http://simlitabmas.ristekdikti.go.id/unduh berkas/RE NCANA \%20INDUK\%20RISET\%20NASIONAL \%2 0TAHUN\%202017-2045\%20\%20\%20Edisi\%2028\%20Pebruari\%202017.pdf

26. K. S. Pribadi, F. Mulyasari, R. Hanifa, A.M.I. Meilano, I. Gunawan, N. Indah, Developing a Program for Strengthening University Role in Contributing to DRR Efforts in the eastern region of Indonesia, Research Center for Disaster Mitigation (PPMB) ITB University Forum for DRR (FPT-PRB), Disaster Experts Conference on DRR Technology \& Policy Sharing in Asian Countries Yonsei University, Seoul, Korea, 19-20 May 2016. (2016). https://repository.kulib.kyotou.ac.jp/dspace/bitstream/2433/217319/1/a59b0p03.pd f 